\title{
BOX 6 | Seamount Ecosystem Evaluation Framework (SEEF): A Tool for Global Seamount Research and Data Synthesis
}

By Tony J. Pitcher, Telmo Morato, Karen I. Stocks, and Malcolm R. Clark

\section{DESCRIPTION OF SEAMOUNT ECOSYSTEM EVALUATION FRAMEWORK (SEEF)}

The Seamount Ecosystem Evaluation Framework (SEEF) is an innovative multidisciplinary tool developed to standardize the parameters by which seamounts are characterized, to report the extent of knowledge about individual seamounts, and to identify and assess threats to them, and to address other issues. Initially developed by Pitcher and Bulman (2007) and Pitcher et al. (2007), SEEF identifies critical gaps in knowledge and may be used as a guide to develop future research plans for a specific seamount. By systematizing sets of seamount data, it can also promote and assist consistent seamount ecosystem modeling, meta-analysis, and, for management, development of ecosystem-based plans.

SEEF is available to the scientific community and general public through the SEEF Web site (http://www. seamounteef.org), and through the Seamounts Online initiative (http://seamounts.sdsc.edu; Stocks, 2009). Using this interface, individuals can update the existing knowledge of a specific seamount, thus contributing to an improved framework. The SEEF version presented here incorporates revisions to the original schema made by a group of participants at the March 2009 Seamount Biogeosciences Network Workshop held at Scripps Institution of Oceanography (http://earthref.org/ events/SBN/2009/).

SEEF incorporates three different parts. The first part (Part A in Figure 1) scores the extent of our knowledge about individual seamounts by listing their most important attributes, including geological, oceanographic, and ecological features that are found on seamounts that may contribute to their role in enhancing local biomass and biodiversity. The second part of SEEF (Part B in Figure 1) scores the relative severity of threats posed by human activities to the abundance and diversity of seamount resources, principally fishing and other extractive exploitation. Effectively, it identifies seamounts in different conservation states. Parts A and B are scored by experts in the field; scoring disagreements can lead to productive research and useful expressions of uncertainty. The left-hand side of Figure 1 lists attributes and issues. A full description is available on the SEEF Web site.

The third part of SEEF (C), currently under development, aims to quantify each attribute and threat using actual values, or categories of values, in a fuzzy logic system. In doing so, SEEF will determine the extent of local enhancements in the food web, biodiversity, or biomass, and at the same time will quantify the different threats posed to seamount ecosystems.

Scores can be color coded, so that scanning or mapping a set of SEEFs immediately reveals the extent of our ecological ignorance as well as the location of threatened seamount areas. At the same time, it highlights gaps in understanding of general seamount ecosystems, promotes seamount data synthesis, and thus uses and contributes to existing online data sets such as Seamounts Online.

\section{SEEF EXAMPLE}

Figure 1 shows a preliminary SEEF application for 15 seamounts in the Atlantic and Pacific oceans. Parts A and B are shown as color-coded bars; keys to colors are at the right. Part A consists of scores for 12 geological, 3 oceanographic, and 25 ecological attributes of each seamount. Color coding indicates the degree of knowledge of each attribute, where

Tony J. Pitcher (pitcher.t@gmail.com) is Professor of Fisheries, Fisheries Centre, Aquatic Ecosystems Research Laboratory, University of British Columbia, Vancouver, Canada. Telmo Morato is Research Fellow, Department of Oceanography and Fisheries, University of the Azores, Horta, Faial, Portugal, and is also with the Oceanic Fisheries Program, Secretariat of the Pacific Community, Noumea, New Caledonia. Karen I. Stocks is Research Scientist, San Diego Supercomputer Center, University of California San Diego, La Jolla, CA, USA. Malcolm R. Clark is Principal Scientist, National Institute of Water \& Atmospheric Research, Wellington, New Zealand. 
BOX 6 | Continued...

\section{PART A: SEAMOUNT ATTRIBUTES}

Depth of peak

Depth of surrounding ocean

Height of peak

$\rightleftarrows$ Slope of seamount

Summit shape

Percentage mapped

Age

Proximity to shelf

Proximity to neighbour seamounts

Hydrothermaly active

Major substrate type summit

Major substrate type flanks

$z$ Ocean currents link to shelf

Ucean currents to neighbour seamounts

Taylor cap or other retention mechanism

Chemosynthetic community

Macrophytes present

Hard-corals present

Soft-corals present

Epiphytes present

Sponges present

Other benthic filter feeders

Nutrient upwelling occurs

Phytoplankton enhancement

Zooplankton enhancement

Deep scattering layer organisms entrapped

Zooplankton migrates to fish forage zone

Predators/grazers present

Detritus build-up on summit/flanks

Detritivores present

Demersal fish

Demersal invertebrates

Infauna

Cephalopods

Aggregating deep sea fish

Visiting large pelagic fish predators

Visiting elasmobranch predators

Visiting marine turtles

Visiting mammal predators

Visiting seabird predators

\section{PART B: CONSERVATION STATUS}

Trawl fishery

Bottom longline fishery

ص Handlines

Surface longline fishery

Purse seine fishery

Trap fishery

Coral extraction industry

Other fishery

Corals and benthos damage

Turtle by-catch issues

Shark by-catch issues

Dolphin by-catch issues

Whale by-catch issues

Seabird by-catch issues

Mining

Others

5 Seamount has some legal protection

$z$ Inside an EEZ, proximity to coast

High Seas
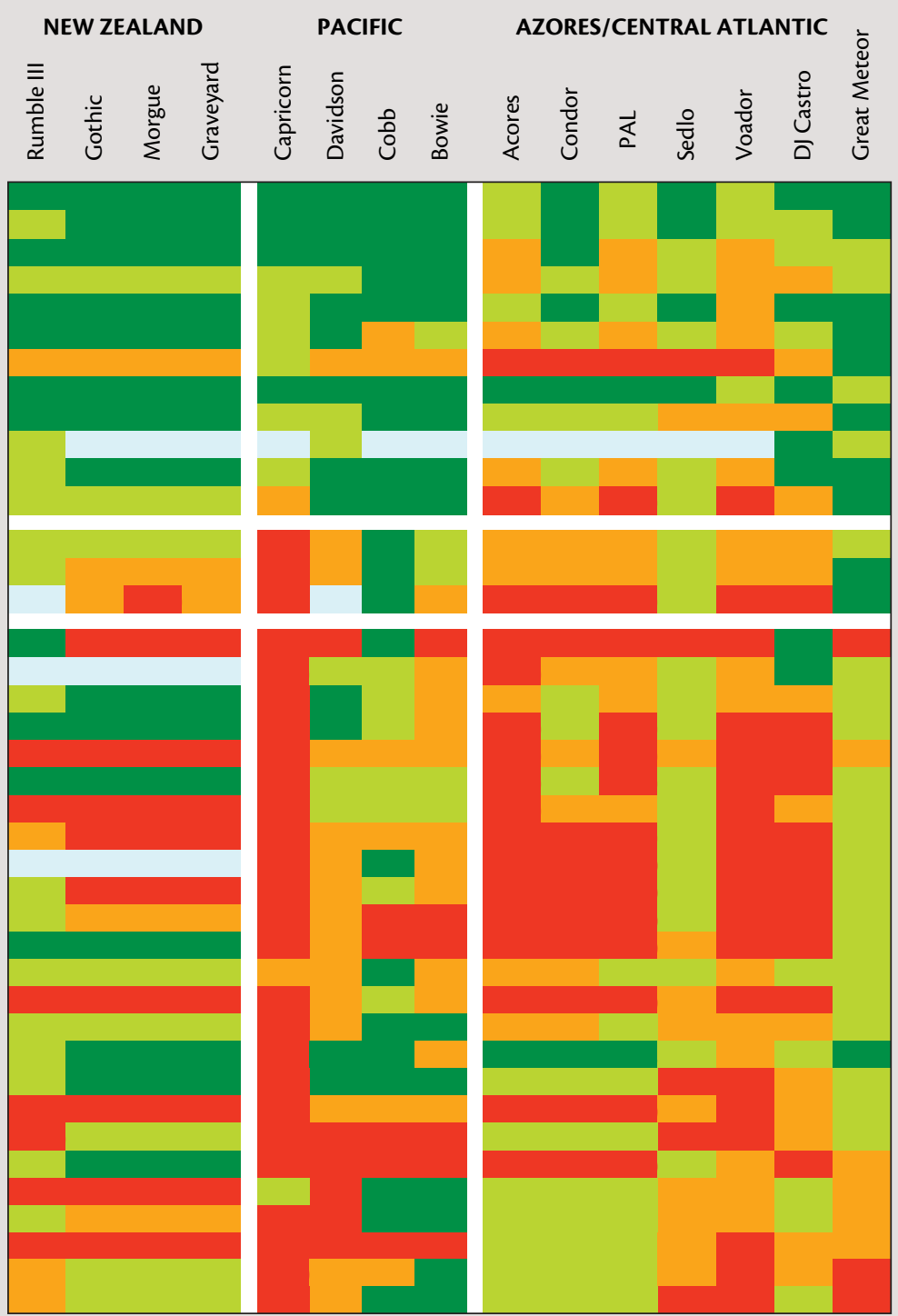

Knowledge Status

not present

unknown

inferred

known

well known

Figure 1. Preliminary Seamount Ecosystem Evaluation Framework for 15 seamounts in the Atlantic and

Pacific oceans. See box text for a detailed explanation of the color coding and data evaluation method.

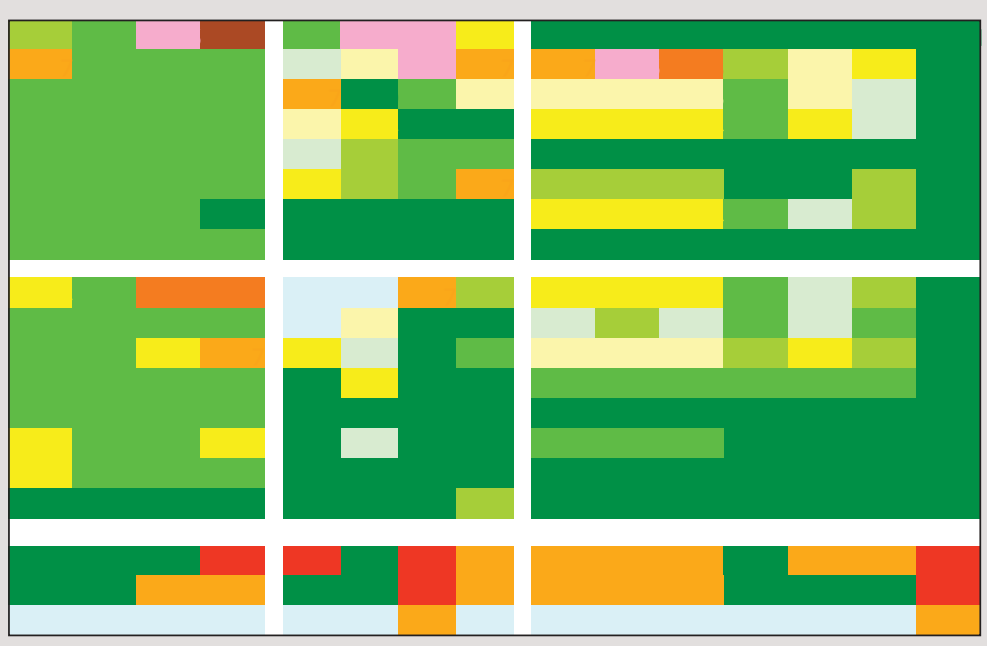

Threat Status

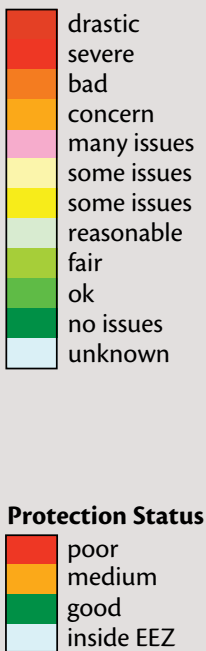


red denotes completely unknown, amber denotes an inferred presence, and shades of green indicate the quality of information available; mauve signifies known absence of this feature.

Conservation status and threats to each seamount are scored in Part B, using scores for eight fishery sectors, eight conservation issues, and three protection status indicators. Items are scored on a ten-point scale of severity, from green to dark red. Here, unknowns are shaded mauve. Eight fishery sectors, eight conservation issues, and three protection status indicators are listed. Alarm signals are immediately evident from those seamounts with red codes in the threats section. For example, in New Zealand, Graveyard Seamount has a severe threat from trawling, Morgue and Graveyard (see Spotlight 7 on page 146 of this issue [Clark et al., 2010]) seamounts exhibit coral damage, while in the Azores, Princesa Alice (PAL) Seamount is threatened by bottom longlines.

Some general features may be quickly visualized from the color-coded SEEF scores. For example, New Zealand and mid-Atlantic seamounts appear to be better known than our examples in the Pacific. The conservation status of Azores seamounts appears to be somewhat better than those of New Zealand seamounts, while the Pacific seamounts are intermediate to these. However, the SEEF scores for these areas must be regarded as preliminary findings because the few examples we have been able to score are not likely to be representative. To increase the utility of SEEF, readers are invited to add scores for seamounts with which they are familiar and add them to examples on the SEEF Web site.

\section{REFERENCES}

Clark, M.R., A.A. Rowden, I. Wright, and M. Consalvey. 2010. Spotlight 7: Graveyard seamounts. Oceanography 23(1):146-147.

Pitcher, T.J., and C. Bulman. 2007. Raiding the larder: A quantitative evaluation framework and trophic signature for seamount food webs. Pp. 282-296 in Seamounts: Ecology, Conservation and Management. T.J. Pitcher, T. Morato, P.J.B. Hart, M.R. Clark, N. Haggan, and R.S. Santos, eds, Fish and Aquatic Resources Series, Blackwell, Oxford, UK.

Pitcher, T.J., T. Morato, P.J.B. Hart, M.R. Clark, N. Haggan, and R.S. Santos. 2007. The depths of ignorance: An ecosystem evaluation framework for seamount ecology, fisheries and conservation. Pp. 476-488 in Seamounts: Ecology, Conservation and Management. T.J. Pitcher, T. Morato, P.J.B. Hart, M.R. Clark, N. Haggan, and R.S. Santos, eds, Fish and Aquatic Resources Series, Blackwell, Oxford, UK.

Stocks, K. 2009. SeamountsOnline: An online information system for seamount biology. Version 2009-1. World Wide Web electronic publication. http://seamounts.sdsc.edu. 